A major purpose or the I ecnnical Information Center is to provide the broadest dissemination possible of information contained in DOE's Research and Development Reports to iusiness, industry, the academic community, and federal, state and local governments.

Although a small portion of this report is not reproducible, it is being made available to expedite the availability of information on the research discussed herein.

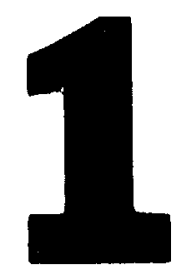


TITLE:

\title{
NEAR.IDEAL LASING WITH A UNIFORM WIGGLER
}

\author{
LA-UR $--88-3586$
}

DE89 003465

$\begin{array}{ll}\text { AUTHOR(S): } & \text { R. W. Warren } \\ & \text { D. W. Feldman } \\ & \text { J. E. Sollid } \\ & \text { W. E. Stein } \\ & \text { W. J. Johnson }\end{array}$

A. H. Lumpkin

J. C. Goldstein

W. J. Johnson

SUBMITTED TO: $\quad$ 10th International Free-Electron Laser Conference, Jerusalem, Israel, August 29-September 2, 1988

\section{DISCLAIMER}

\begin{abstract}
This report was prepared as an account of witk spon sored by an agency of the Unitod situtes Government. Netther the United Stules (invermment nor any agency thereof, nor any of their employses, makes any warranty, expreas or implied, or assumes uny legul liability or reaponsibility for the accuracy. completeness, or usefulncss of any information, upparatus, product, or process disclowed, or represents that its use would not infringe privately owned rights. Reference herein to any spocific commercial product, process, or service by trade name, trademark. manufacturer, or otherwise doen not necessarily constitute or imply its endorsement, recommendation, or favoring by the Unitod States (jovernment or any agency thereor. The views and opinions of authors expressod herein do not necessurily state or reflect those of the Unilod Statea Government or any agency theroof.
\end{abstract}

iecceptence of this aricle. thu p'solisher recognizes that the US Government ratans a nonexclusive, royalty-free hicense to publish or reproduce the blished form of this contribution or to allow others to do so for US Government purposes

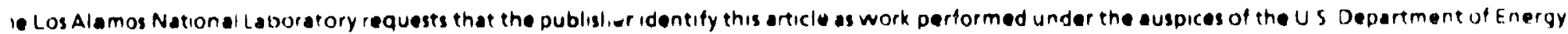

L(O)S ANIITOS

os Alamos Nationall aboratory Los Alamos, Now Mexico 87545

\section{MASTER}

IISTRARIIIUN OF IHIS DOLIUMENI IS UMLIMIII? 


\section{NEAR-IDEAL LASING WITH A UNIFORM WIGGLER*}

Roger W. WARREN, Jon E. SOLLID, Donald W. FELDMAN, William E. STEIN, W. Joel JOHNSON, Alex H. LUMPKIN, and John C. GOLDSTEIN

Los Alamos National Laboratory, MS H825, Los Alamos, NM 87545, USA

Over the years the Los Alamos FEL team has reduced or eliminated many of the experimental problems that resulted in non-1deal lasing. The major problems were accelerator instabilities that cause noise and fluctuations in current, energy, and timing; wakefield effects in the wiggler and beamline that introduce fluctuations in the beam's energy; and mirı or nonlinearities caused by free carriers produced in the mirror by the high light levels, which caused extra light losses and interfered with the diagnostics. Lasing is now thought to be ideal in that it lacks major disturbing effects and is limited only by emittance, energy spread, and peak current. In this paper we describe the features of lasing that we have nbserved over a range of optical power of 1000 , from the onset of lasing, to the threshold of the sideband inztability, to the organization of regular optical spikes, to the region of chaotic spikes. Cavity-length detuning is presented as an ideal technique, in most circumstances, to completely supress sidebands. With detuning one can easily switch operating modes from that giving the highest efficiency (chaotic spiking) to that giving the narrowest spectral line (no sidebands). Aiternative techniques for siduband supression normally use some kind of wavelength selective device (e.g., a grating) inserted in the cavity. With detuning, there is no need for such a device, and, therefore, no conflict between the wavelength control exerted by this extra optical component and thiat exurted by the energy of the electron bam. Lasing, therefore, starts easily, a shift in wavelength, i.e., chirp, is easily accomplished, and the consequences of inadequate control of the electron beam energy are not severe.

\section{Introduction}

Several experimental teams have sucessiully operated an FWI, using a variety of wigglers and have achieved significant powor levels and other interesting results. The original lasing was accomplished [ 1 ? by the team at Stanford, and they have made careful reports of their resulta $|2,3|$ und analysis [4]. There has been, however, a scarcity of papers since then describing more rocent lasing in detail and carofully comparing measured resulta with theoretical predictions. Thin lack has been especially true with respect to experimental results that show synchrotron sidebands. In many cuses,

- Work supported and funded by the US Department of Defense. Army Strategic Defense Commund, under the auspices of the US Dopart tront of Finorgy. 
the experimenters have encountered considerable difficulty in coaxing FFLs to perform well. In others, the experimertal parameters were not adequate to display especially interesting ésults. To show sidebands, for example, the micropulse and macropulse must exceed some critical length.

A careful comparison is sometimes foiled by the lack of necessary theory or the difficulty in performing adequate computer simulations. Simulations are usually less useful than analytical solutions, and it has, so far, been found to be impractical (because of memory and speed limitations of even the largest computers) to perform simulations that treat three-dimersional FEL problems in whicn a wide frequency spectrum is also included. In spite of these limitations, there is abundant theoretical work by Colson[4-9], Goldstein[10,11], Tang and Sprangle[12,13], Quimby[14, 15], Kroll, Morton, and Rosenbluth[16-19], their coworkers, and others describing lasing and sidebands under a variety of conditions.

Over the years, we at LANL have eliminated most of the experirnental difficulties that have interfered with such a careful comparison. We have reduced fluctuations in enerby, curront, and timing in our accelerators that introduced noise [20] that obscured the results of interest. We have largely eliminated wakefield effects that triggered synchrotron oscillations in the wigglers and caused growth in emittance [ 21$]$ and energy spread in the beamline. We have avoided large nonlinear absorption [22] in the ZnSe dielectric mirrors we previously used by replacing then with copper These nonlinear effects falsified our optical diagnostics and gave incorrect power levels and efficiencies. We are one of the few Laboratories [23] that has consistently observed and rejorted $[10,24,26]$ sidebands.

The purposes of this paper are fourfold: to convince the reader that sidebands are not only real, but are an almost unavoidable feature of laging; to provide details of our experimental results on lasing with a uniform wiggler to assigt others who might conte inplate using systems similar to ours; where possible, to make a careful serni-quantitative comparison of our results with any theory or simulation that is available, identifying topics of agreement and disagreenent; and to propose explanations for effects that we observe, even in the absence of supporting ihoory. Clearly we are taking risks in proposing explanations and, as ever, encourage more simulations and more theoretical work on the many topics that we discuss.

The rest of the paper is divided into the following sections: 2. Experimental apparatus and procedures, 3. Limitations of the experiment, 4. Cavity length detuning, 5. Chirp, 6. Lasing at different currents, 7. Discussion of the results, 8 . Conclusions.

\section{Kxperimental apparatus and procedures}

'The accolerator we use has been described elwewhere $|28|$. Its important churacteriaticy are the following: 
- The micropulse is $10 \mathrm{ps}$ long and contains up to $5 \mathrm{nC}$ of charge, i.e., a peak current of $500 \mathrm{~A}$.

- The macropulse contains about 2000 micropulses, separated by $46 \mathrm{~ns}$. The macropulse is about $100 \mu$ s long, i.e., long enough so that lasing I eaches saturation, develops sideband structure, and undergoes chirp.

- The rms emittance of the beam ( $\sim 2 \pi \cdot \mathrm{mm} \cdot \mathrm{mrad}$ unnormalized) and energy spread $(\sim 1.5 \%$ FWH.M) are small enough to give good lasing performance but still have a significant degrading effect on gain and efficiency.

- The start up of the accelerator is a messy operation. About $10 \mu \mathrm{s}$ is required to ramp the accelerator's energy to its final value and stabilize the feedback system. During this time, the amplitude and frequency of lasing shift around in an erratic manner. Because of these variations, the details of gain and frequency chirp are obscured for the fir st $10 \mu \mathrm{s}$ of operation.

- The major kinds of noise and fluctuations in the electron beam are of two sorts: fast noise that shows up as variations between adjacent micropulses, and slow noise that represent a variation over the whole macropulse. Fast fluctuations have been observed as follows: in beam energy - less than $0.1 \%$, in current - less than $1 \%$, and in tirning - iess than 1 ps. Slow variations in these parameters are 2-5 times larger. Fluctuations in beam position and focusing appear to be small. All of these fluctuations are, in most situations, small enough so that they have only a minor effect on lasing. We have worked for years to reduce noise to these levels. It is not generally realized how stringent the requirements on fluctuations are for near-ideal lasing and that their realization is one of the most demanding tasks in the engineering of FEL systems.

The wiggler used in these studies [27] is $1 \mathrm{~m}$ long, its wavelength is uniformly $2.73 \mathrm{~cm}$, and its peak field is $0.30 \mathrm{~T}$. It is lined with a 1 -m-long stainless steel tube to shield the electron bcam from wakefields.

The optical cavity is $7.0 \mathrm{~m}$ long and is usually terminated by copper mirrors with a combined 108 (including minor vignetting losses) of about 4 to at the nominal lesing wavelength of $10.6 \mu \mathrm{m}$. The Rayleigh distance of the mirrors is about $0.5 \mathrm{~m}$. An $-1 \cdot \mathrm{mm}$-diam hole in the center of one of the mirrors couples light out of the cavity to our diagnostic system [28]. When the cavity power is low, the outcoupled light is monitored with a He cooled IIg doped Ge, detector. At higher levels, various pyroelectric detectors are used, some of them in connection with an optical spectrometer whose resolution is better than $0.2 \%$ at $10 \mu \mathrm{m}$. Among other quentities, the in cavity power and efriciency of the laser can be calculated from the optical signal measured oxternally. Aa a cineck, the effeciency is also determined by messuring the energy loss suffered by the olectron bean. Agreement of the two efficiencies is usually achiever within $20 \%$ 
Because of the wide range of parameters covered in our experiments, we need to condense our results for this report in some systematic fashion. We have chosen to emphasize two of the most important parameters, electron current and cavity length, and their effecis on efficiency and optical spestra. Although we also routinely record high-resolution data on electron energy spectra $[29,30]$, we have chosen, for this paper, to delete most of these data because of the less detailed information they contain. We firsi present samples of our results at a constant current but various cavity lengths. We then present results at zero cavity detuning and various currents.

\section{Limitations of the experiment}

We have referred to this paper as a semi-quartitative comparison of experiment and theory. A more quantitative comparison is frustrated by experimental limitations. The calibration of currentmeasuring devices has a large uncertainiy. Several important parameters are difficult to measure and so have been measured only occasionally. Examples are emittance and micropulse width. We estimate an accuracy for these quantities of about $30 \%$.

A. more important limitation is related to our optical measurements made near $10 \mu \mathrm{m}$. The sensitivity near $10 \mu \mathrm{m}$ is poor because, in most cases, photon $\mathrm{i}$ of this wavelength cannot be cnunted. Thus, streak cameras cannot be used and no direct evidence of the shape of an optical micropulse is available. We also have difficulty performing measurements of optical spectra as they evolve temporally during a macropulse, and we usually settle for an integr l over the macropulse. Crude information concerning temporal evolution is obtained by changing the length of the macropulse. This limitation is important because in gume cases we need to discriminato between a compler spectrum caused by sidebands, i.e., several frequencies generated s' multaneously, and one caused by chirp, i.e., several îrequencies generated sequentially.

Many theories or simulations do not include important features of our experiment. An example is the threo dimensional nature of a micropulse. Many theories and simulations are zero ciimensional, ignoring the longitudinal pulged nature and the transverse shape. Otherg are onedimensional, ignoring the transversc shape. Most cannot handle a wide frequency range. As will be diecused below, we have discovered that cavity length detuning is a very promising technique for eliminating sidebands. This strategy is completely overlooked whenever the pulsed nature of the current is ignored, for example, by theories employing periodic boundary conditions.

\section{Cavity length deturing}

The variation in lasing power and efficiency with cavity length has been of interest from the carliest FFL, experimenta [ I 3|. Considerable effort | 4 | has been spent trying to bring these experimental and theoretical results into agreement. F'ig. 1 shows a one-dimensional calculation of in cavity optical power versus cavity detuning for our experimental conditions al a micropulae charge of ' $\mathrm{nC}$, an emittance of $1 \mathrm{a}$ inm mrad, and zero energy spread. Fig. 2 shows a lypical detuning 
curve from our experinent under similar conditions. The horizontal scales of both curves are the same and zero detuning on fig. 2 has arbitrarily been chosen to match the peak power. The similarities in the general shape of these spectra are striking. In each c8se, the spectrum corresponding to the peak of the curve is dominated by sidebands covering a wa velength range of over 10\%. In contrast, in each case the spectrum in the long plateau at short cavity lengths is completely free of sidebands. The calculated curve does not always agree so well with experiment, but shows great sensitivity to common variables such as energy spread and also to unexpected ones such as the exact noise model used to generate the spontaneous emission that starts the lasing.

Some of the present authors have explained [31] the mechanism by which detuning supresses sidebands. In compressed form, the explanation is that sidebands grow primarily from the discontinuity presented by the leading edge of a micropulse, and more weakly from low-level noise in the body of the micropulse. Shortening the cavity has two beneficial effects. It continuelly shifts the leading-edge discontinuity forward on the optical micropulse out of overlap with the electron micropulse, reducing its gain. Secondly, any noise in the body of the micropulse is similarly shified forward and thus has a limited time to grow before it is also shifted off the leading edge of the pulse.

The dt ails of the detuning curve are complex. In the plateau of fig. 2, marked $A$, the spectrum, shown in fig. 3, is narrow ( $\sim 5 \%$ FWHM) and approximates the transform limit of a 10 -ps pulse. Simula ins [10] are in agreement with this spectral narrowing with detuning. In a narrow region around $B$, where the detuning is small, two narrow sidebands, shown in fig. 4, develop around the mair: line. These sidebands are separated from the main line by $-2.0 \%$. For slightly less detuning near point $C$, a series of narrow, evenly spaced sidebands develops (shown in fig. 5) that is the signature of the spiking mode [25], i.e., a situation in which the optical micropulse contains short regions of very high power separated by longer regions of very low power. The spacing between the spectral lines of fig. 5 is $2.7 \%$, i.e., within a few percent of $1 / N$, where $N=36$, the number of wiggles in the wiggler. This separation is special because with it, every electron injected into the wiggler is overtaken by one and cnly one spike at some place in the wiggler. The spike forces the electrons to execute half a synchrotron cycle at the spike's very high power level, extracts an unusually large amount of energy from the electrons, and corcentrates it in the short length of each spike.

Figs. 6 and 7 give the results of a simulatıon we have performed showing a spiking mode with a spectrum similar to fig. 5. Shown in fig. 6 is the spectrum and in fig. 7 the temporai profile of the micropulse. The spikes in fig. 7 are roughly evenly spaced, the peak intensity, $-150 \mathrm{GW} / \mathrm{cm}_{2}$, and peak power, $-10 \mathrm{GW}$, are five times the average values in the micropulse, and each spike is about 10 optical cycles long.

At smaller detunings, simulations by Colson [9] and by us show that the spikes become stronger, narrower, and closer together. but, chaotic in their amplitude and timing so that the regular spacing of their spectral lineg is washed out. The overall spectral envelope, however, keeps the 
roughly triangular shape of figs 5 and 6 , but covers a greater range of wavelengths. Our measurements agree with this generalization, and we see spectral widths in excess of 10\%, i.e., twice the width of fig. 5. We can estimate the optical power in these chaotic spikes from the way in which we expect regularly-spaced spikes to scale with spectral width, i.e., twice the spectral width implies half the spike width ( 5 optical cycles) and 16 times the peak power (above $100 \mathrm{GW}$ ).

A secund way to estimate the peak power in a spike is to examine the electrons' energy spectrum. Fig. 8 is processed data that show the electron energy spectrum before and during lasing. The long tail on the lasing curve shows that chaotic spiking causes the electrons to lose up to about $8 \%$ of their original energy. If each spike is half a synchrotron period long, scaling arguements indicate that the spike's power level must be around $50 \mathrm{GW}$. When detuning is employed to eliminate spikes, the energy spectrum is compressed: the maximum energy lost by an electron is then $2 \%$ or so. Additional support for this enormous power level in the spikes is the observation tilat chaotic spiking at high power levels is usually accompanied in our experiments by sparks on the refiecting surfaces of the mirrors. The sparks indicate the existence of high optical fields and undoubtedly tend to linnit the peak fields somewhat.

The regularly spaced spectral lines of the spiking mode achieved with moderate detuning do not normally appear alone but, as in figs. 5 and 6 , include a remnant (marked with a star) of the narrow line of fig. 4 with its weak sidebands. We believe that in this detuning range the optical micropulse is quite complex, as shown in fig. 9, containing regions that are heavily spiked and regions that are relatively smooth. Reduced detuning shifts the structure on this curve to the left, displaying more spikes, whereas increased detuning shifts it to the right, displaying more of the narrow line spectrum.

\section{Б. ' nirp}

Fig. 10 shows the results of zero-dimensional calculation of the efficiency of our wiggler as a function of optical power with an electron beam energy spread of $1.5 \%$. Curve $A$ is calculated at a wavelength of $10.6 \mu \mathrm{m}$, the wavelength for maximum small-signal gain. It shows a series of maxima and minima that reflects the electrons passage through several cycles of svnchrotron motion. Curve $B$ is the envelope of curves like $A$, but calculated at other wavelengths. The corresponding wavelengths are lisced at several points on curve B. The optical power labeled D is special. It is the power 'about $40 \mathrm{MW}$; that gives the electrong one-haif a synchrotron oscillation down the length of the wiggler. The efficiency, $0.6 \%$, or curve $A$ for this power is nearly the maximum value obtained The shape of curve $A$, especialiy at low power levels, is quite sensitive to electron energy spread $A t$ zero spread, for example, the peak of curve $\mathrm{A}$ has the value $1.0 \%$ and occurs at a power of $15 \mathrm{MW}$, in better agreement with predictions of Morton |16| and Kroll, Morton, and Rosenbluth |17, 18| that estimate an efficiency there of $1 /(2 N)(14 \%)$ 
The power labeled $E$ is also special, corresponding to one synchrotron oscillation of the electrons down the wiggler. This power, $300 \mathrm{MW}$, is about 10 times that of $\mathrm{D}$ (16 times at zero energy spread). Whenever the optical pulse is modulated by the synchrotron motions at the power $E$, each electron passing through the wiggler feels exactly one complete cycie of the modulated optical wave. Simulations show that under these conditions, the modulation of the optical pu se does not remain small, but increases gruatly in magnitude, developing into the spiking mode. Thus this power level represents the threshold for the spiking mode. Finally, to orient the reader, region $F$ of curve $B$ corresponds roughiy to the cperating conditions we find when lasing while detuned with a narrow line. In contrast, region $\mathrm{G}$ corresponds to our conditions while spiking with minimal detuning.

Curve $B$ of fig. 10 shows that the efficiency of this wiggler can exceed $1 /(2 \mathrm{~N})$ if the lasing wavelength can shift to longer wavelengths once lasing has started and reached a significant power level. Such a shift in wavelength (chirp) coinpensates for energy loss by the electrons as they pass down the wiggler. Curve $C$ is approximately the envelope of curve $B$. It is a plot of one-quarter of the separatrix (bucket) height and is proportional to the optical power raised to the one-fourth power. It is obviously important to determine if chirp can actually occur so that the efficiency and wavelength follow curve B, and to ide.atify the mechanism for the chirp.

We have tentatively identified three such mechanisms. The first is important during the initial few microseconds of growth, before saturation of any kind occurs. Here lasing is linear such that many different modes with different frequencies can grow independently. Their growth rates depend upon the excess of gain over loss for each mode. This mechanism causes light generation to shift from its initial frequency distribution, that typical of spuntaneous emission, to the longer wavelength peak of the small-signal gain. It also causes wavelength shifts in response to variations in experimental paramevers. If the electron energy varies during this short period, as it usually does, the peak of the gain curve shifts, the growth rates of the different modes also shift, and the average frequency of lasing chirps.

The second mechanism is connected with sideband generation and phenomena occurring at the front of the micropulse. Goidstein has shown [11 | that chirp can occur through a multistep hopping process: a weak long-wavelength sideband is generated from the main line, most of the new light generated is added to the sideband, it grows to be the gtrongest line snd may develop a long wa velength sideband of its own. Successive repeats of the above steps, i.e., hops, can occur. Two varieties of this process have been observed in simulations: one in which each new strong line in the hopping process dominates its pregenitor so that the final spectrum is shifted to longer waveler.gths but is relatively narrow. A second variety is the spiking mode, appearing at higher powers, in which all of the strong lines are prese $\cdots$, giving a "picket fence" like spectrum as in fig. 6 . In either case, the centroid of the spectrum shifts to give a higher efficiency 
We call the third mechanism frequency creep. It invoives phenomera occurring at the end of the optical micropulse and is most important when detuning is large. If the cavity is made shorter than the ideal length, the overlap of the electron and optical beams decreases. The optical pulse enters the wiggler ahead of the electron pulse. eeps slipping further ahead, and by the time the electron pulse reaches the end of the wiggler, preceeds it by a significant amount. To maintain lasing, light must somehow be generated by the electrons in the end of the wiggler where overlap by the optical pulse is weak. This generation is accomplished by coherent spontaneous emission, i.e., spontaneous emission from electrons that were well bunched at the front of the wiggler. Such light has a broader spectrum than laser light and serves as a seed for shifting the wavelength to a region of higher efficiency in response, for example, to a shift in electron energy. Coherent spontaneous emission of this sort is not generated if the cavity length is adjusted to be too long. This difference between a short and long cavity is the cause of the asymmetrical shape of the detuning curve.

Simulations have been performed that demonstrate chirp by creep [11]. We report here an experiment to test this mechanism. We adjusted our system to lase with $\sim 30 \mu \mathrm{m}$ of detuning at a power level of $\sim 0.3 \mathrm{GW}$ in a narrow spectral line. We forced the energy of the accelerator to change linearly during the macropulse by various amounts up to $\pm 0.5 \%$. We monitored the width of the spectrum, integrated over the macropulse; fig. 11 shows our results. If no chirp had occurred, the line would always be $0.2 \%$ wide, i.e., the transform limit. If chirp oceurred readily, the line would increase its width and change its shape in an easily calculable way, according to the solid curve. From the experimental points, it is clear that about the expected amount of chirp cecurred verifying the existence of a chirp mechanism that does not depend upon sidebands. The chirp, however, appears to be asymmetric, fitting the curve for positive energy slew but falling below it, ie- indicating a reluc ance to chirp, for negative slew. The mechanism for chirp-by-creep, described above, is consistent with this asymmetry. Spontaneous emission generates light at a shorter wavelength than gain does. Thus the seed for chirp, nentioned above. favors chirp to a shorter wavelength. The chirp required to be consistent with curve $B$ of fig. 10 , however, involves a slew to longer wavelengths and thus occurs slowly.

Our conclusions concerning chirp are that under most conditions chirp can occur and shifts the frequency of lasing to one of higher efficiency. If detuning is small, chirp occurs through sidebands and the hopping mechanism; if it is large, chirp occurs through the creep mechanism. In special cases, for example, at low power where sidebands do not occur and detuning is small, chirp is very slow or does not occur at all on the time scale of our macropulse.

\section{B. Lasing at different power levels}

While lesing with zero cavity detuning (the detuning that produces the highest powcr), we have varied the charge in the electron micropulse from about 1 to $3.5 \mathrm{nC}$. These variations carsed the 
micropulse-average intercavity power level to increase from zero to $\sim 1 \mathrm{GW}$ and the efficiency of lasing from zero to $-1 \%$. Fig. 12 shows this dependence of power and efficiency on charge and current. Most notable in fig. 12 are the threshold charge for lasing and the oscillatory nature of the power and efficiency that mimic the oscillations shown in the zero-dimensiunal calculations of fig. 10 . The efficiencies plotted in fig. 12 are generally much smaller than those of fig. 10 because of the threedimensional nature of the real pulses (extensive wings in transverse and longitudinal directions with low currents and low efficiencies). At most power levels the reduction in efficiency for three versus zero dimensions is about a factor of 3 . A careful comparison [32] of the efficiencies of our experimental measurements with zero-, one-, and thre $\epsilon_{\text {- }}$-dimensional theories shows reasonable agreement.

Detuning curves were measured at all of the points plotted in fig. 12 and their shapes were all roughly the same as fig. 2 . Their widths, however, varied in a regular manner, being roughly proportional to optical power. In all cases, a moderate detuning prodiaced a narrow $(\sim 0.2 \%)$ spectral line. Using other mirrors and higher micropulse charges, we have exceeded an in-cavity power of 2 GW, an efriciency of $1.6 \%$, and a small signal gain of $200 \%$.

The initiation of lesing in an FEL and the onset of sidebands is discussed by Bogomoloy et al. [33] and by Antonsen et al. [34]. Their theories are analytical at low power levels and numerical at high. All calculations were done in zero dimensions, i.e., the pulsed nature was ignored. Both authors find that lasing starts when the current is high enough so that the small-signal gain exceeds the cavity losses and that at this threshold the spectrum is narrow because only a few longitudinal modes of the cavity have gain that excceds loss. As the current is increased, the spectrum broadens because more and more modes have gain that exceeds loss. Then at large enough currents, nonlinear saturation effects cume to be important, and mode competition takes place in which the mode with the largest gain dominates the other modes and supresses their gain. Normally this saturation gives a sudden reduction in spectral width. Under some conditions, however, this spectral narrowing occurs very slowiy or not at all [34]. The authors call this lack of spectral narrowing a phase instability.

Both authors find a threshold for the sideband instability when the optical power has increased to the point where the electrons $\mathbf{B}^{0}$ through one-half a complete synchrotron cycle in the wiggler's length. As the current is increased further, they find that the sidebands become organized into regularly spaced lines, i.e., the spiking mode. At even higher currents, tho spikes luse their rezular spacing and become more chaotic.

We have observed mogt of the effects at zero detuning, and they are similar to those discussed above for significant detuning. They have been investigated theoreticaliy, particularly by authors cited above, i.e., Colson, Kroll, Morton, Rosenbluth, Goldstein, Sprangle, and Quimby with their coworkers. 
During a typical experiment, lasing starts at a micropulse charge of $0.75 \mathrm{nC}$. Because of the small excess of guin over loss, lasing is ragged over the macropulse until the charge is increased enough to raise the peak optical power above $5 \mathrm{MW}$. The efficiency is very low and the spectrum is approximately Gaussian with a spectral width (FWHM) of about $0.6 \%$. If the cavity length is detuned, the spectrum remains at the same wavelength but narrows to $\sim 0.3 \%$. As we increase the micropulse charge to $0.8 \mathrm{nC}$, the optical power increases to $15 \mathrm{MW}$, and the efficienc', to about $0.04 \%$, but the spectral widths for zero and significant detuning behave as before. The differences in width caused by detuning could be related to the phase instability discussed by Antonsen, iut we believe, instead, that it indicates an unusually short (5-ps) optical micropulse at low power and zero detuning but a str etch in micropulse length from 5 to $10 \mathrm{ps}$ caused by the detuning. In support of this interpretation, simulations by Goldstein [11] and Colson [6] show a large increase in micropulse width of this kind with detuning as do the 1983 Stanford measurements [3].

Above a charge of $0.9 \mathrm{nC}$ and a power of 20-30 MW, there is an a .-upt change in the spectra. Fig. 13 shows an example. The spectrum contains a small bump at a wavelength marked $A$ and then a broad ( $\sim 1 \%$ FWHM) line extending about $1.5 \%$ to wavelengths longer than $A$, peaking about $0.9 \%$ aboye $A$. The detuned spectruin is still $\sim 0.3 \%$ wide and is nositioned at the wavelength marked $A$. The efficiency has increased by a factor of $\sim 3$. At still higher currents, the efficiency increases further and gradual changes occur in the width of the spectra up to a power of several hundreds of megawatts. The shape stays about the same. The detuned spectrum is still narrow and at $A$.

We suggest that the abrupt change in the spectra is caused by the sideband instability and that detuning eliminates the instability. Thus lasing starts at wavelength $A$ and then rapidly chirps to a longer wavelength of higher efficiency. The instability was predicted by Antonsen to occur at onehalf synchrotron oscillation, i.c., at about $40 \mathrm{MW}$ according to fig. 12. Simulations by Colson [8] for our wiggler predict the instability at $-26 \mathrm{MW}$. We observe it around $20-30 \mathrm{MW}$. We feel that the agraement is remarkably good.

Theoretical prodictions concerning the spectra's shape can be compared with these results. Simple th.eories [34] suggest that at threshold the sideband should be narrow and displaced from the main line by $\mathrm{I} /(2 \mathrm{~N})(1.4 \%)$. More complete theories [19] s'ggest that a featureleas broadbend of sidebends should grow, well separated from the initial lize and displaced by up to $1 /(2 \mathrm{~N})$. As the optical power increases, the band of growing sidebands should broaden and extend to longer wavelengths. Simulations performed by us give spectral shapes very similar to fig. 13. All of these predictions are in semiquantitative agreement with our observations.

It should be emphasized that at zero detuning we do not see the sharply defined sideband structure predicted by many simulations [8], i.e., a strong main line with one or both sidebands. Wo did repsrt seeing such a structure years ago [24], but now believe that these experiments were 
dominated by wakefield effects and demonstrate the ability of wakefields to excite synchrotron oscillations in situations where they would otherwise be absent.

As the optical power exceeds $500 \mathrm{MV}$, two new features are observed. First, as shown in fig. 14, the spectrum develops a multihumped structure reminiscent of fig. 6 showing spikes, but with washed-out structure. Second, the sharp spectral line generated with detuning no longer lies at the short wa velength side of the multihumped, zerc-detuning spectrum, but now lies close to the center of it. We suggest that the onset of the multihumped structure near $500 \mathrm{MW}$ is a sigin of the second threshold (expected around $300 \mathrm{MW}$ ) where the electrons undergo a full synchrotron oscillation. We alse suggest that for power levels below $500 \mathrm{MW}$ the sharp detuned line cannot chirp easily and so stays fixed in wavelength during a macropulse, hut that for these higher powers it can chirp and shift to a longer wavelength of higher efficiency.

Finally, we should emphasize the stochastic nature of the sideband instability. All of the spectra that display the instability are erratic in that their general character is fixed, but the details of their shape vary fro $n$ shot to shot by $30 \%$ or so. The spectra obtained with detuning are, in contrast, very regular and reproducible. The amplitude of the macropulse shows this same kind of variation. Fig. 15, for example, shows a cagged macropulse correlal3d with sideband instabilities while fig. 16 shows a smooth one correlated with a narrow line spectrum. These differences have found general support in simulations. For example, two simulations were run with zero detuning, using conditions identical except for the spontaneous emission noise seed. Their spectra differ by about the $30 \%$ observed in our experiments and the razgedness of their macropulses were large and completely different from each other.

\section{Discussion of resulte}

The results of this experiment were influenced by the length of wiggler, the electron beam energy, the micropulse length, the wavelength employed, and other variables. If, for example, a wiggler three times shorter had been used, the sideband instability would not have occurred until power levels nearly 100 times higher, i.e., about 2-3 GW, had been reached. If the wavelength generated had been ten times shorter, the 10-pe micropulse would have included about 3000 optical cycles and its frequency spectrum could be as narrow as $0.03 \%$. The inevitable variations in electron energy during a macropulse would cause chirp that would almost surely broaden this transformlimited width. Because of these kinds of sensitivit ies, we cannot assume that the measurements we have made will be typical of results from other FELs. In partic llar, we have shown that detuning is a technique that works admirably to supress sidebunds and produce spectra at the transfurm limit, but we have not shown that this stratezy is applicable to all situations. Simulations should be performed to explore a wider range of experimental parameters to test this possibility. 
The reduction in efficiency obtained with a uniform wiggler and detuning (about a factor of 3 ) is undesirable but is not a special fea ture of the detuning technique. It has been argued [31] that any other technique that is sucessful in eliminating s:debands, e.g., narrow-band filters or diffraction gratings placed in the cavity, necessarily reduces the efficiency by about the same amount. From our simulations and the results of measurements to be presented in another paper [35] at this conference, we find that detuning works even better for lapered wigglers than for uniform ones. It still suceeds in completely supressing sidebands, but instead of reducing the efficiency of a tapered wiggler, detuning increases it. In contrast to alterrative supression techniques, no extra hardware is needed and there is no conflict between the wavelength that is determined by the electron's energy and the wavelength chosen by the extra wavelength-selective component inserted into the cavity. In experiments we have performed with an intercavity grating [22], this conflict made lasing unnecessarily difficult.

In comperison to a tapered wiggler, a uniform wiggler has much to recommend it. The small signel gain and detuning range are large, making it easy to start. it can readily be switched from the detlined mode in which light with a narrow spectral range is genorated to the synchronous mode in which light is generated with high efficiency and spikes of very large peak power are found. The efficiency is not limitad to $1 /(2 \mathrm{~N}$ ), but because of chirp and (when detuning is small) because of spiking, car: exceed this value at high enough powers. Because of the difierent ways in which efficiencies scale for uniform and tapered wigglers, however, the most efficient wigglers will probably g.lways be made long and tapered.

\section{Conclusions}

We have operated an FEL using a uniform wiggler over peak nower levels from about 5 MW to, perhaps, $50 \mathrm{GW}$. We have ideniified the threshold for the sideband instability and have seen evidence of a second threshold for the spiking mode. With a detuned cavity, we have seen clcar evidence for both the periodic and chaotic spiking modes and can easily generate a narrow spectral line of transform limitod width. We have identified several difforent inechanisms for chirp and have observed them experimentally. We have establishod detuning as a practical means to eliminate the sideband instability. Wo find, in general, good agreement with theory and simulations. F'urther work should be carriod out in inany areas, in particular to reuch a better theoretical understanding of detuning and chirp.

\section{Acknowledgments}

The experinntal program at Los Alamos is supported by a ded: sated crew without which the experiment would fail. We nwe our gratitude, in particular, to Roy Norris, Larry Haynes, John Hornkohl, Noel Okay, and Scott Apgar. 


\section{References}

[1] D.A.G. Deacon, L.R. Elias, J.M.J. Madey, G.J. Ramian, H.A. Schwettman, and T.I. Smith, Phys. Rev. Iett. 38 (1977), 892.

[2] J.N. Eckstein, J.M.J. Madey, K. Fobinson, T.I. Smith, S. Benson, D. Deacon, R. Taber, and A. Gaupp, "Additional Experimental Results From the Stanford 3-Micron FEL," PQE8 (1982), 49

[3] S. Benson, D.A.G. Deacon, J.N. Eckstein, J.M.J. Madey, K. Robinson, T.I. Smith, and R. Taber, "Review of Recent Experimental Results From the Stanford 3- $\mu \mathrm{m}$ Free-Electron Laser," J. Phys. 44 (1983), 353.

[4] W.B. Colson, "Optical Pulse Evolution in the Stanford Free-Electron Laser and in a Tapered Wiggler," PQE8 (1982), 457.

[5] W.B. Colson, "The Trapped Particle Instability In Free-Electron Laser Oscillators and Amplifiers," Nucl. Instrum. and Methods Phys. Res. A250 (1986), 168.

[6] W.B. Colson and A. Renieri, "Pulse Propagation in Free-Electron Lasers," J. Phys. 44,(1983), 11.

[7] R.A. Freedman and W.B. Colson, "Long Pulses and Sideband Instabilities in Free-Electron Laser Oscillators," J. Phys. 44 (1983), 369.

[8] W.B. Colson, "Chaotic Optical Modes in Froe-Electron Lasers," SPIE 453 (1983), 290.

[9] W.B. Colson and R.A. Fruodman, "Syuchrotron Iristebility for Long Pulses in Free-Electron Oscillators," Optics Comm. 46 (1983), 37.

[10] J. C. Goldstein, B.E. Newnam, R.W. Warren, and R.L. Shemield, "Comparison of the Results of Thenretical Calculations With Experimental Measurements From the Los Alamos Free-

Electron Laser Oscillator Fixperiment," Nucl. Instrum. and Methods, Phy. Res A250(198\%), 4.

(11) J.C. Goldatoin, "Evolutio:1 of Long Pulses in a Tapered Wiggler Free-Electron Laser," SPIE 453 (1983), 2

112] C.M. Tang and P. Sprangle, "Semi-Analytical Formulation of the 'Two-Dimensional Pulso Propagation in the Froe-Electron laser Oacillator," SPIE 453 (1983), 11

113] S. Riyopoulos and C.M. Tand, "The Free-Eloctron Laser Sideband Instability Reconsidered," Nucl Inntrum and Methods Phys. Kes. A2.59 (1986), 226

114| i).C. Quimby, I M Slater, and J.P Wilcoxon, "Sidaband Suprennion in Free Filactron Lamera With Multiple Synchrotron Poriudn," JQE QE 2! (1985), 979. 
[15] D.C. Quimby, "Sideband Generation and Mode Structures in Free-Electron Lasers," FreeElectron Lasers, Critical Reviews of Optical Science and Technology, Brian E. Newnam, Editor, SPIF, 738, 103 (1988).

[16] P.L Morton, "Relationstip of FEL Physics to Accelerator Physics," PQE8 (1982), 1.

[17] N.M. Kroll, P.L. Morton, and M.N. Rosenbluth, "Free-Electron Lasers With Variable Parameter Wigglers." JQE QE-17 (1981), 1436.

[i8] N.M. Kroll, P.L. Morton, and M.N. Rosenbluth, "Variable Parameter Free-Electron Laser," PQE7 (1979), 89

[19] N.M. Kroll and M.N. Rosenbluth, "Sideband Instabilities in Trapped Particle Free-Electron Lasers," PQE7 (1979), 147.

[20] M.T. Lynch, R.W. Warren, and P.J. Tallerico, "The Effects of Linear Acceler ator Noise on the Los Alamos Free-Electron Laser," JQE QE-21 (1985), 904.

[21] B.E. Carlsten, "Emittance Growth Caused By Bends in the Los Alamos Free-Eleciron Laser Energy Recovery Experiment," Proc. 1987 Pas ticle Accelerator Conf., IEEE Catalog No. 87CH2387-9, E.R. Lindstrom and L.S. Taylor, Eds., 1755 (1988).

[22] J.E. Sollid, D.W. Feldman, R.W. Warren, H. Takeda, S. Gitomer, J. Johnson, and W. Stein, "Sideband Supression in the Los Alamus Free-Flectron Laser Using a Littrow Grating," theso proceedings.

[23] Another report that includes the observation of sidebands is F.G. Yee, J. Masud, T C. Marshall, and S.P. Schlesinger, "Power and Sidehand Studies of a Raman FEL," N"יr!. Instrum. and Methods, Phys. Res., A269 (1986), 104.

[24] R.W. Warren, B.E. Newnam, and J.C. Goldatein, "Raman Spectra and the Los Alamos FreeElectron Laser," JQE QE 21 (1985), 882.

[25] R.W. Warren, J.C Onldatein, and B.E. Nownam, "Spiking Mode Operation For a Uniform Period Wiggler," Nucl. Instrum. and Mcthods, Phys. Res. A2BO(1986), 19.

1261 R.W. Warren, W.E. Stein, M.T. 'ynch, K.L. Shemeld, and J.S. Franer, "The I,os Alamos Free Electron Laser: Accelerator Performauce," Nucl. Inatrum. and Methods, Phys. Kes. A237 (1986), 180

|27| R.W. Wurren, C.A Brau, B E Newhan, W F. Stain, J.O Winaton, und I, M Young. "Statuy of the Free Electron Laner Fixperiment at Inon Alamon," PQQBB (1982), 397 
[28] B.E. Newnam, R.W. Warren, R.L. Sheffield, W.E. Stein, M.T. Lynch, J.S. Fraser, J.C. Goldstein, J.E. Sollid, T.A. Swann, J.M. Watson, and C.A. Brau, "Optical Performance of the Los Alamos Free-Electron Laser," JQE QE-21, 867 (1985).

[29] A.H. Lumpkin and R.B. Feldman, "On-Line Extraction Efficiency Analyses for the Los Alamos Free-Electron Laser," Nucl. Instrum. and Methods, Phys. Res. A259 (1987), 19.

[30] R.L. Sheffield, W.E. Stein, R.W. Warren, J.S. Fraser, and A.H. Lumpkin, "Electron Beam Diagnostics and Results for the Los Alamos Free-Electron Laser," JQE QE-21 (1985), 895.

[31] R.W. Warren and J.C. Goldstein, "The Generation and Supression of Synchrotron Sidebands," submitted Proc. Ninth Int. Free-Electron Laser Conf., Williamsburg, Va., Sept. 14, 1987.

[32] R.W. Warren, D.W. Feldman, B.E. Newnam, S.C. Bender, W.E. Stein, A.H. Lumpkin, R.A. Lohsen, J.C. Goldstein, B.D. Mcvey, and K.C.D. Chan, "Recent Kesults from the Los Alamos Free-Electron Laser," Nucl. Instrum. and Methods, Phys. Res. A259 (1987), 8.

[33] Ya.L. Bogomolov, V.L. Bratman, N.S. Ginzburg, M.I. Petelin, and A.D. Yunakovsky, "Nonstationary Generation in Free-Electron Lasers," Optics Comm. 36 (1981), 209.

[34] T.M. Antonsen, Jr., and B. Levush, "Mode Competition and Supression in Free Elactron Laser Oscillators," submitted to Physics of Fluids.

[36] D.W. Feldman, H. Takeda, R.W. Warren, J.E. Sollid, W.E. Stein, and W.J. Johnson, "High Extraction Efficiency Experiments With the Los Alamos Free-Electron Laser, " these proceedings. 


\section{FIGURE CAPTIONS}

Fig. 1. Simulated in-cavity optical power va cavity length detuning.

Fig. 2. Experimental in-cavity optical power vs cavity length detuning.

Fig. 3. Experimental narrew spectral shape for large decuning near $\mathbf{A}$.

Fig. 4. Experimental spectrum showing weak sidebands for mod srate detuning near $B$.

Fig. 5. Experimental spectrum showing multiple, evenly spaced sidebands for small detuning near $C$.

Fig. 6. Simulated spectrum to be compared with fig. 5.

Fig. 7. Simulated micropulse shape correeponding to fig. 6.

Fig. 8. Experimental data showing the electron energy spectra before and after lasing when chaotic spiking occurs.

Fig. 9. Suggegted shape of optical micropulse corresponding to fig. 6.

Fig. 10. Zero-dimensional calculation of efficiency vs optical power at the wavelength of the peak of the small-signal gain and other wavelengths.

Fig. 11. Experimental measurement of spread in lasing wavelength vs extent of steady variation in energy of electrons during macropulse.

Fig. 12. Experimental variation of lasing power and efficiency vs micropulse charge.

Fig. 13. Experimental spectrum just above threshold for sideband ins ability.

Fig. 14 Experimental spectrum above second threshold.

Fig. 16. Experimental measurement of optical power vs time in the macropulse with zero detuning

Fig. 16. Experimentul measurement of optical power vg time in the macropulse with large detuning 

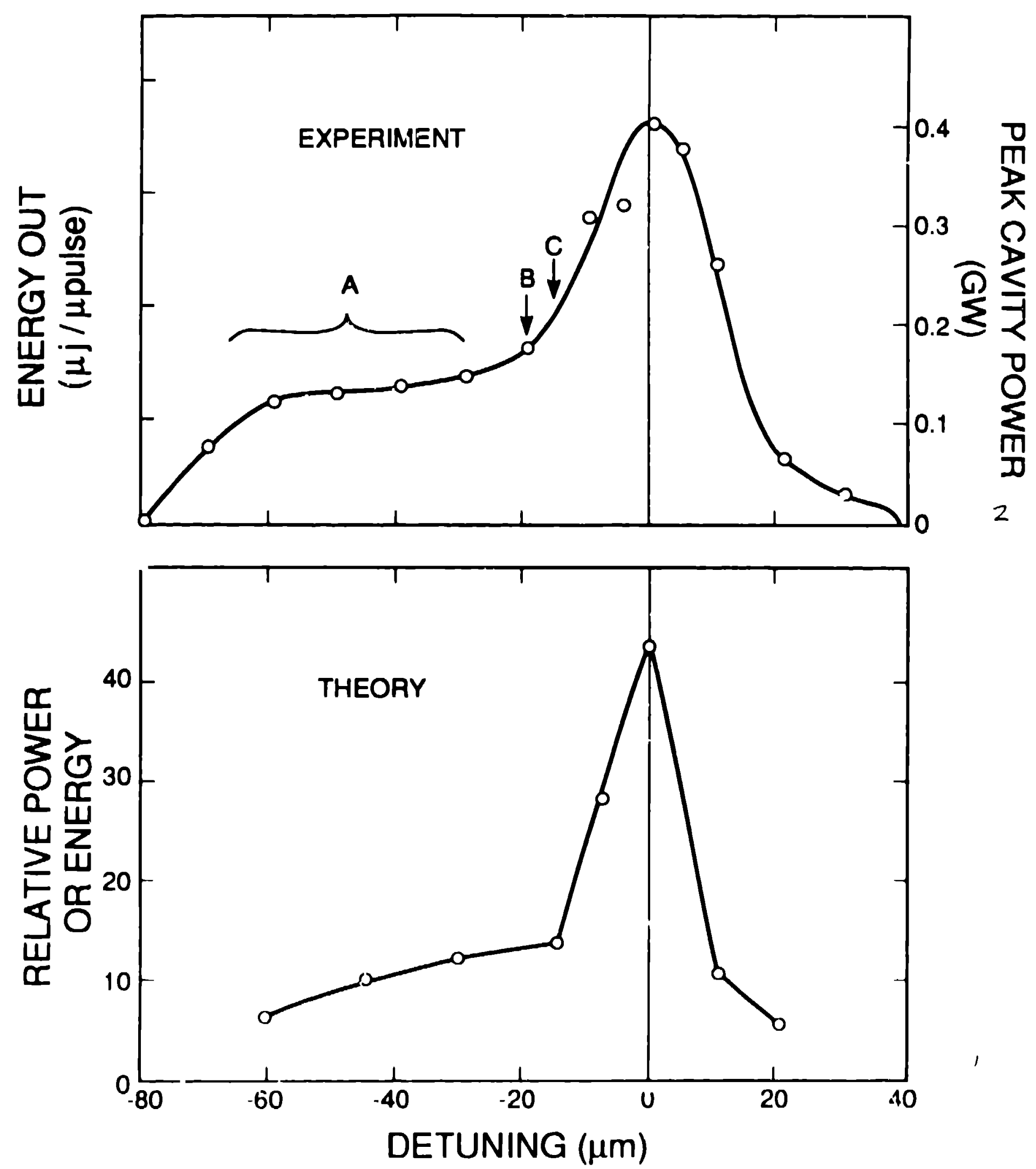


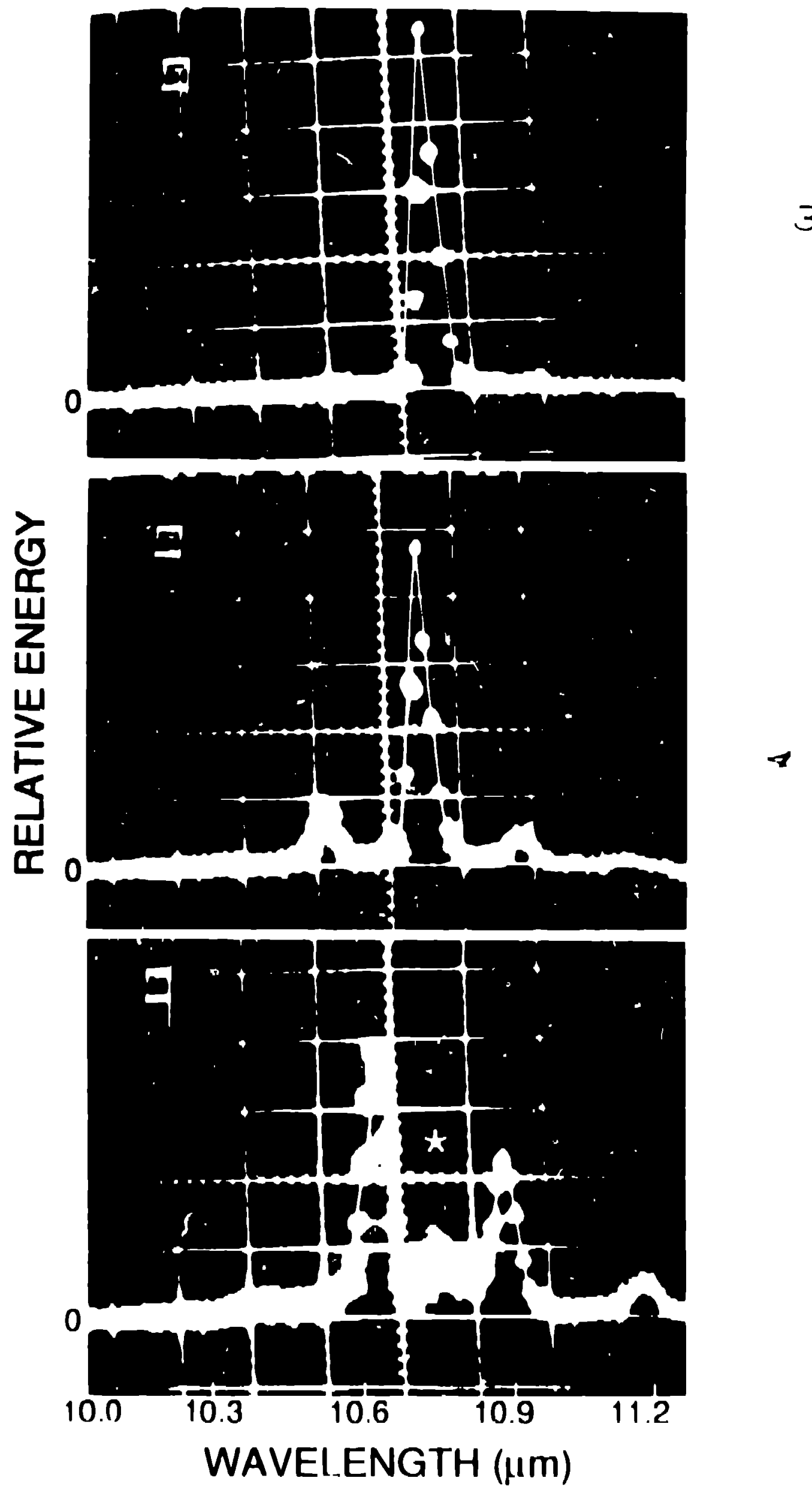

$r$ 

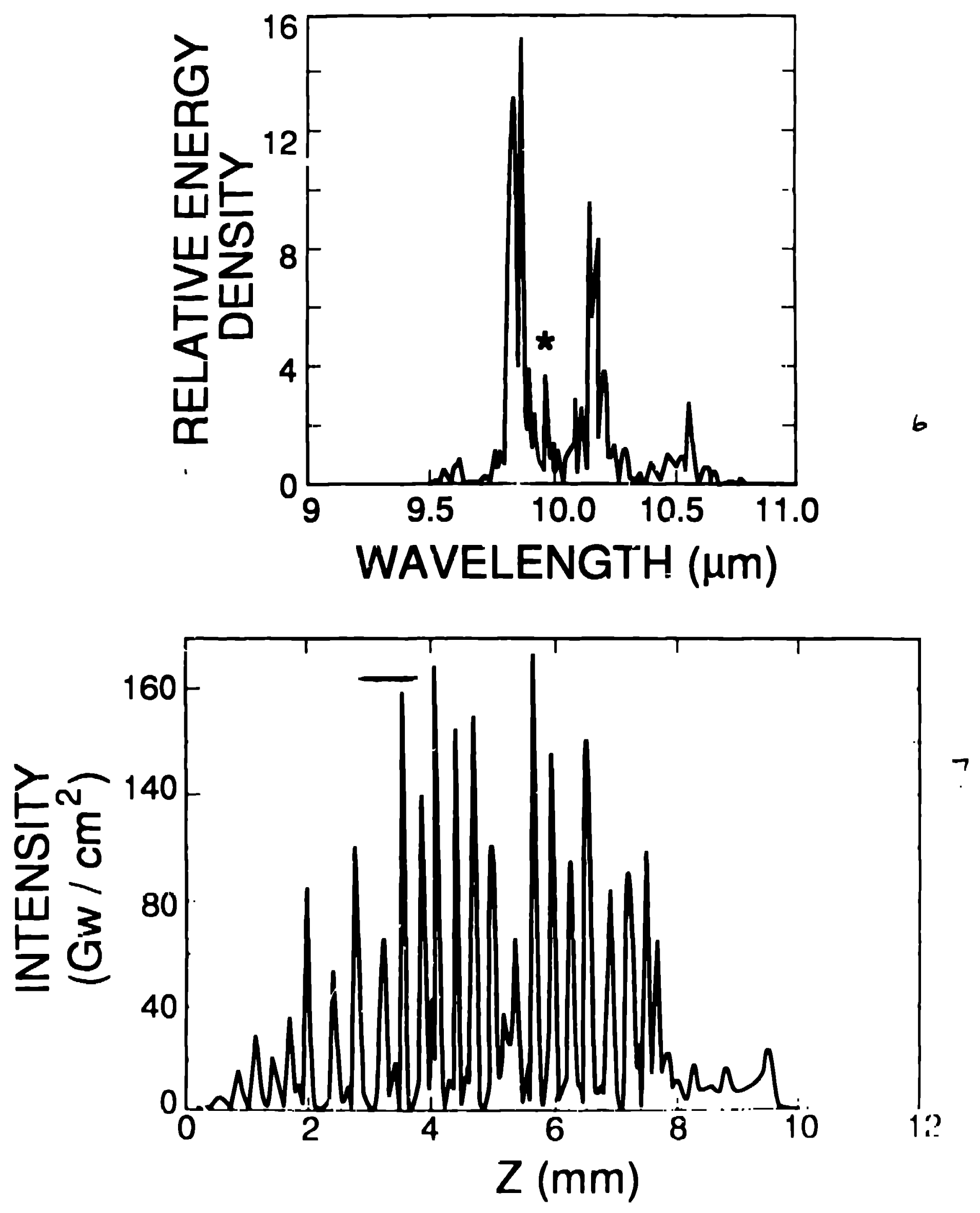


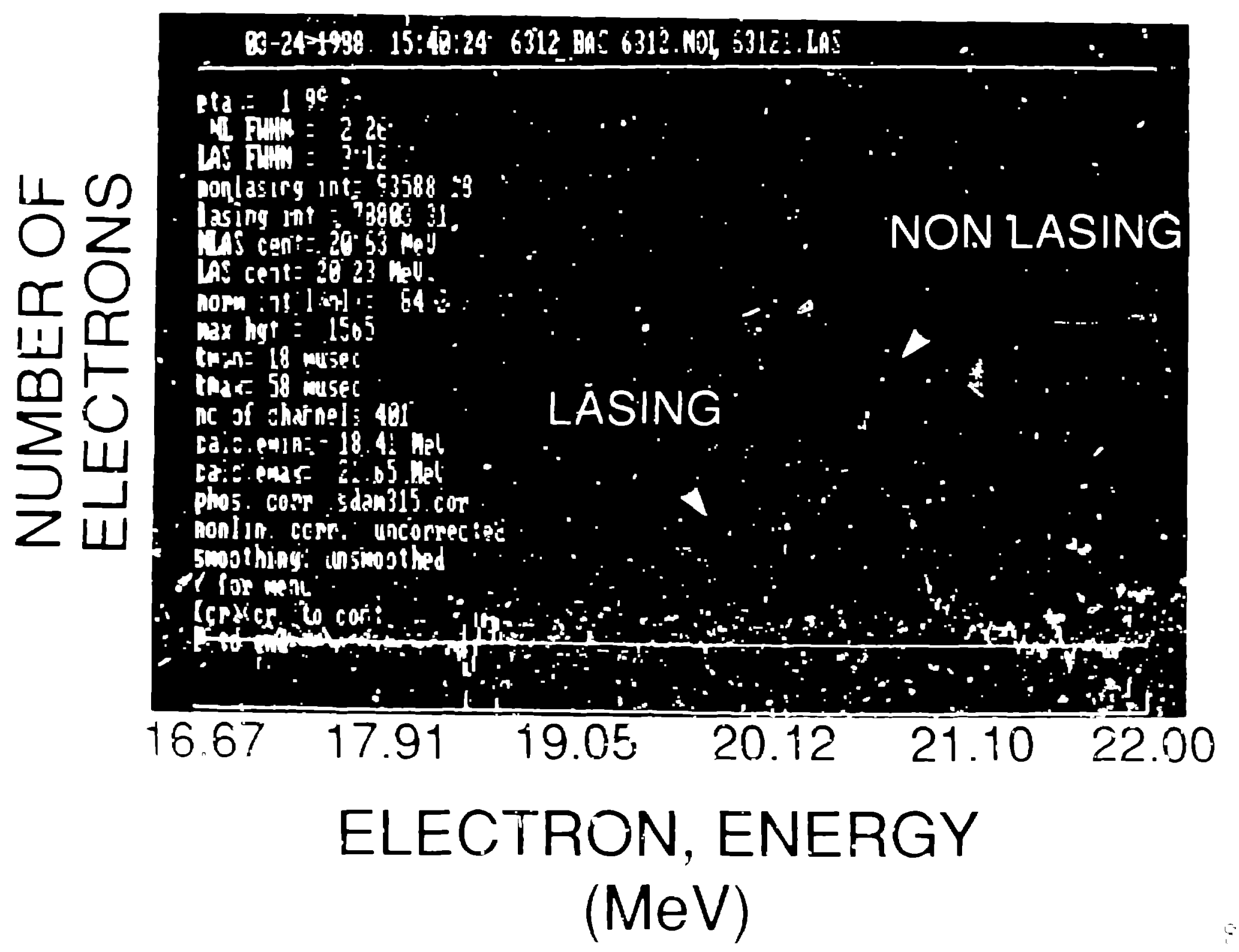




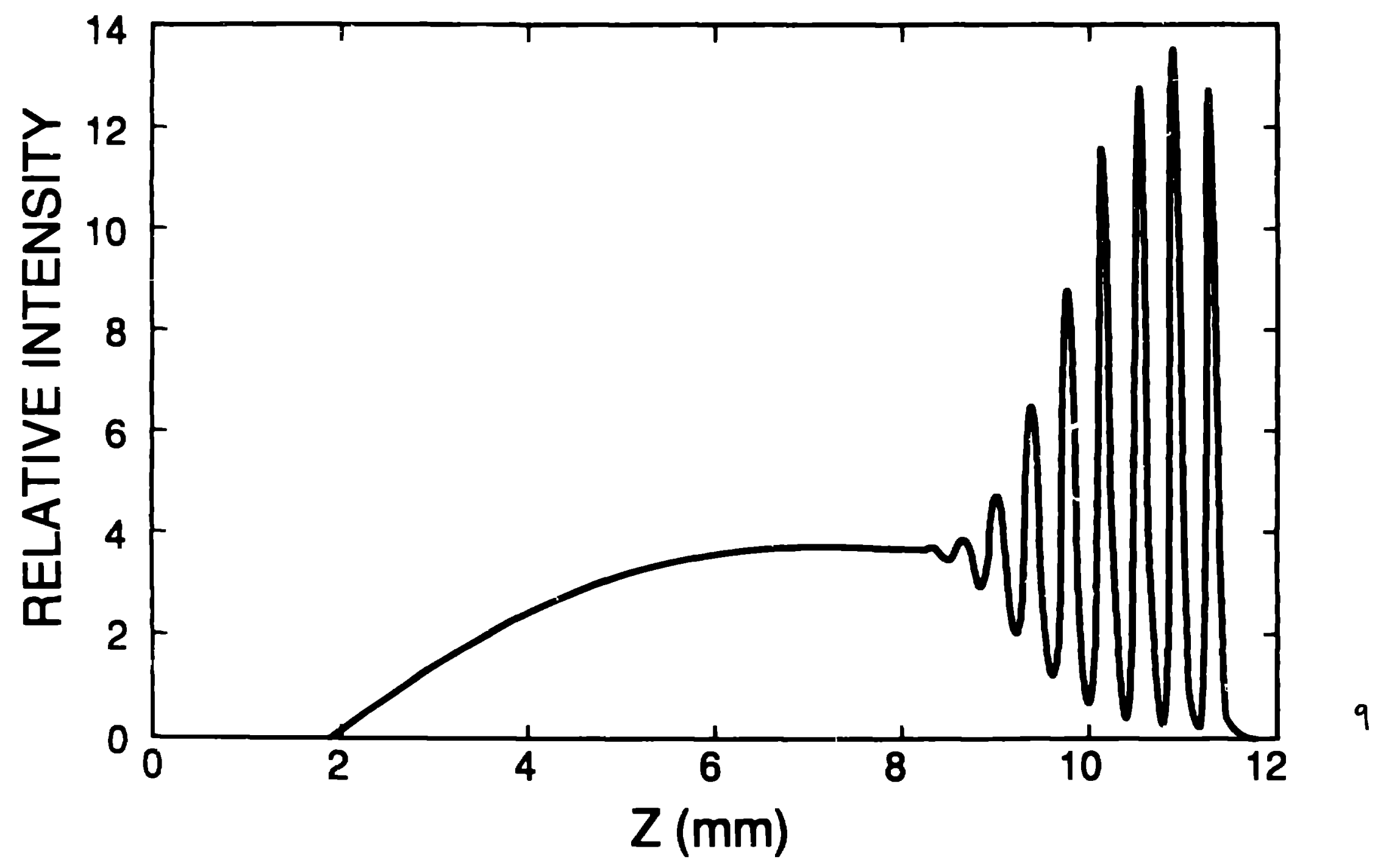




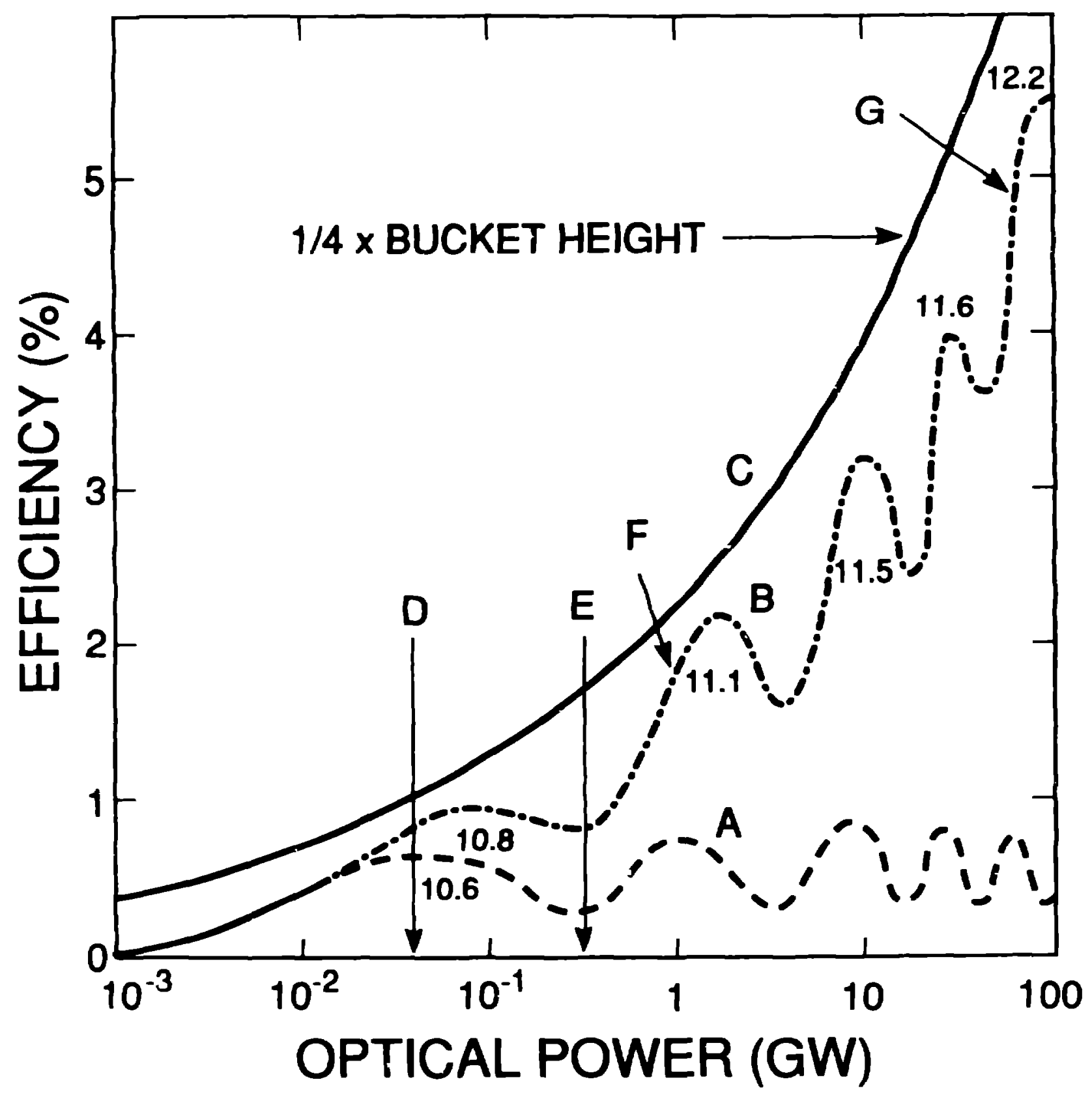




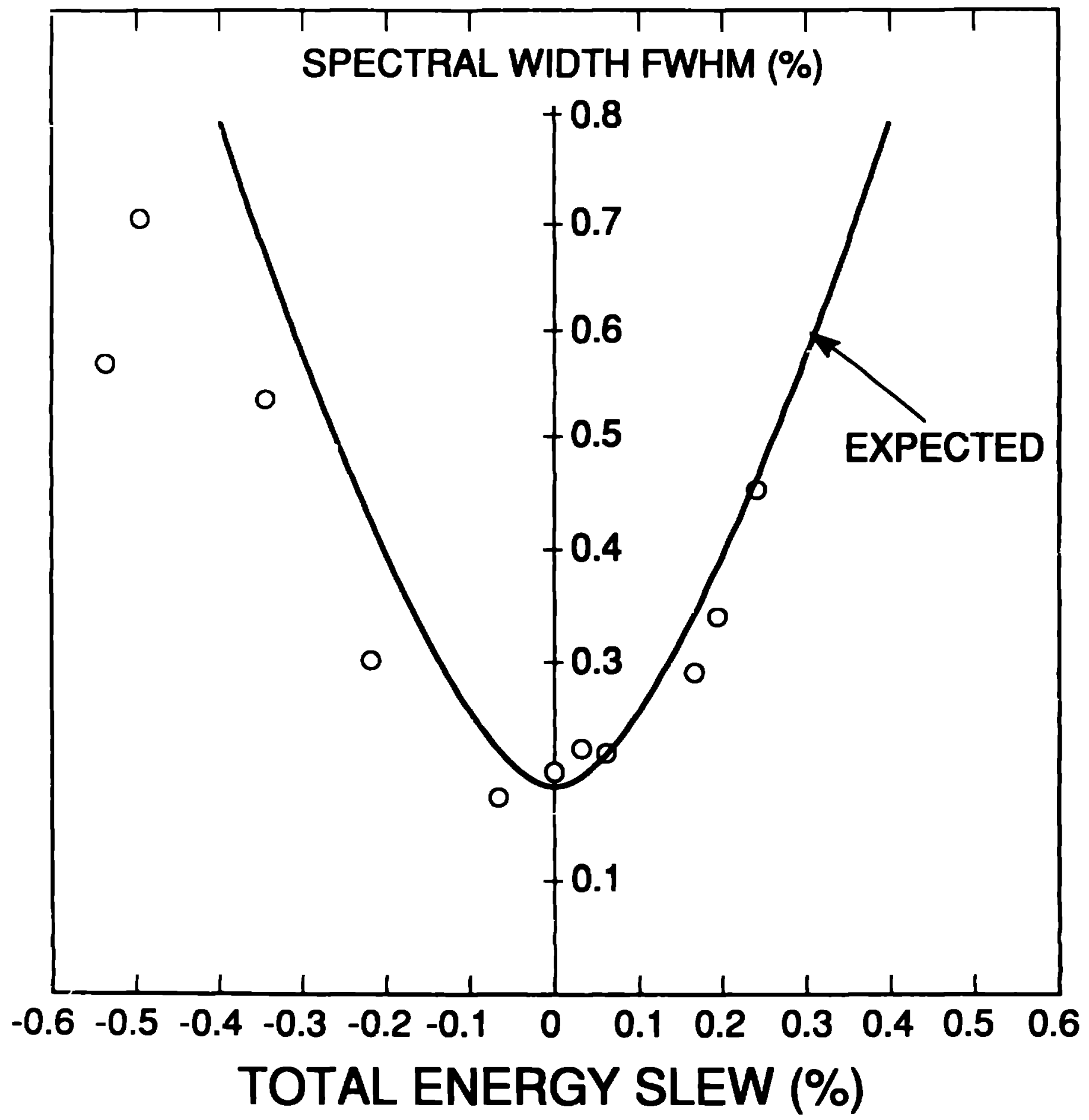




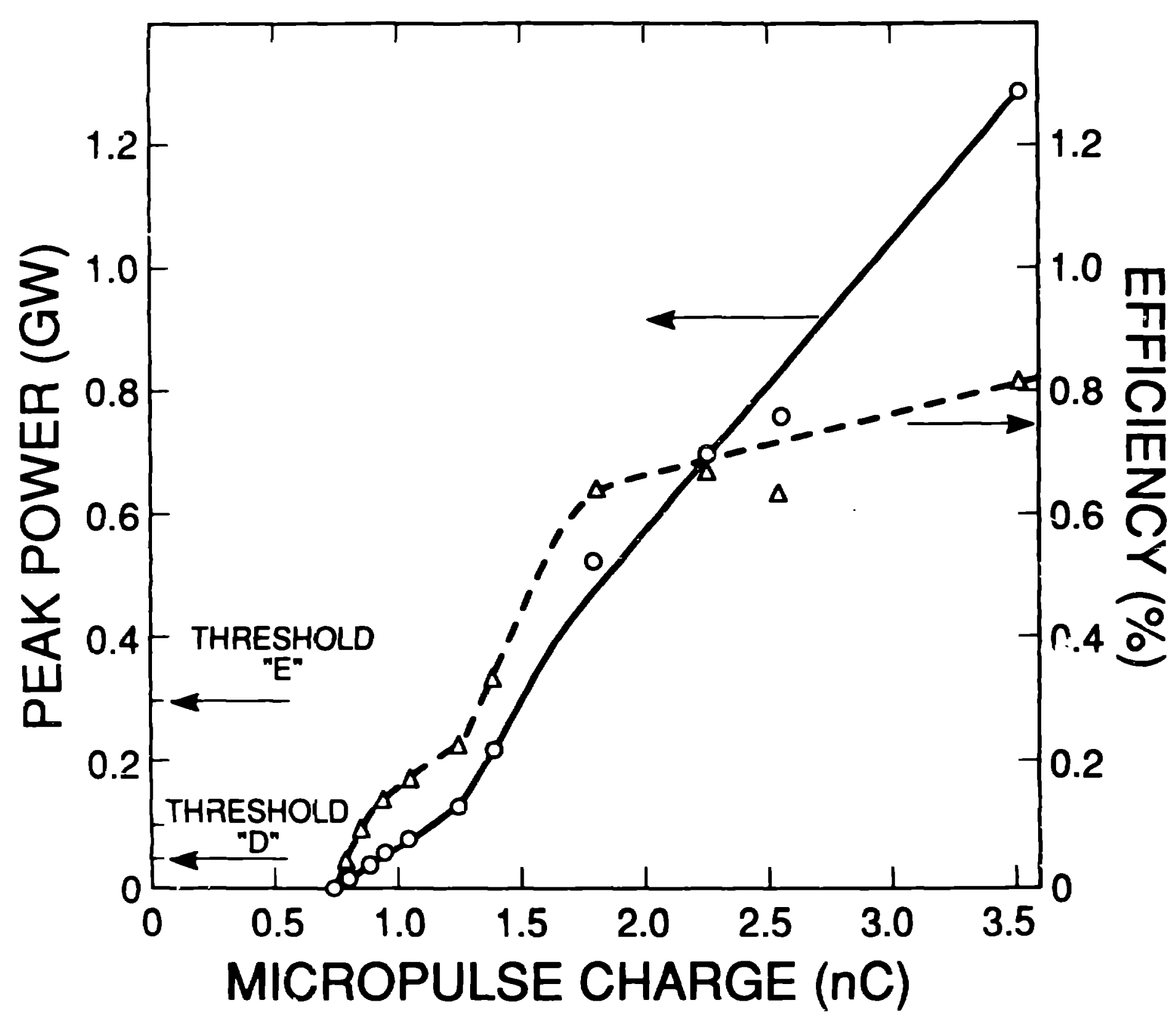




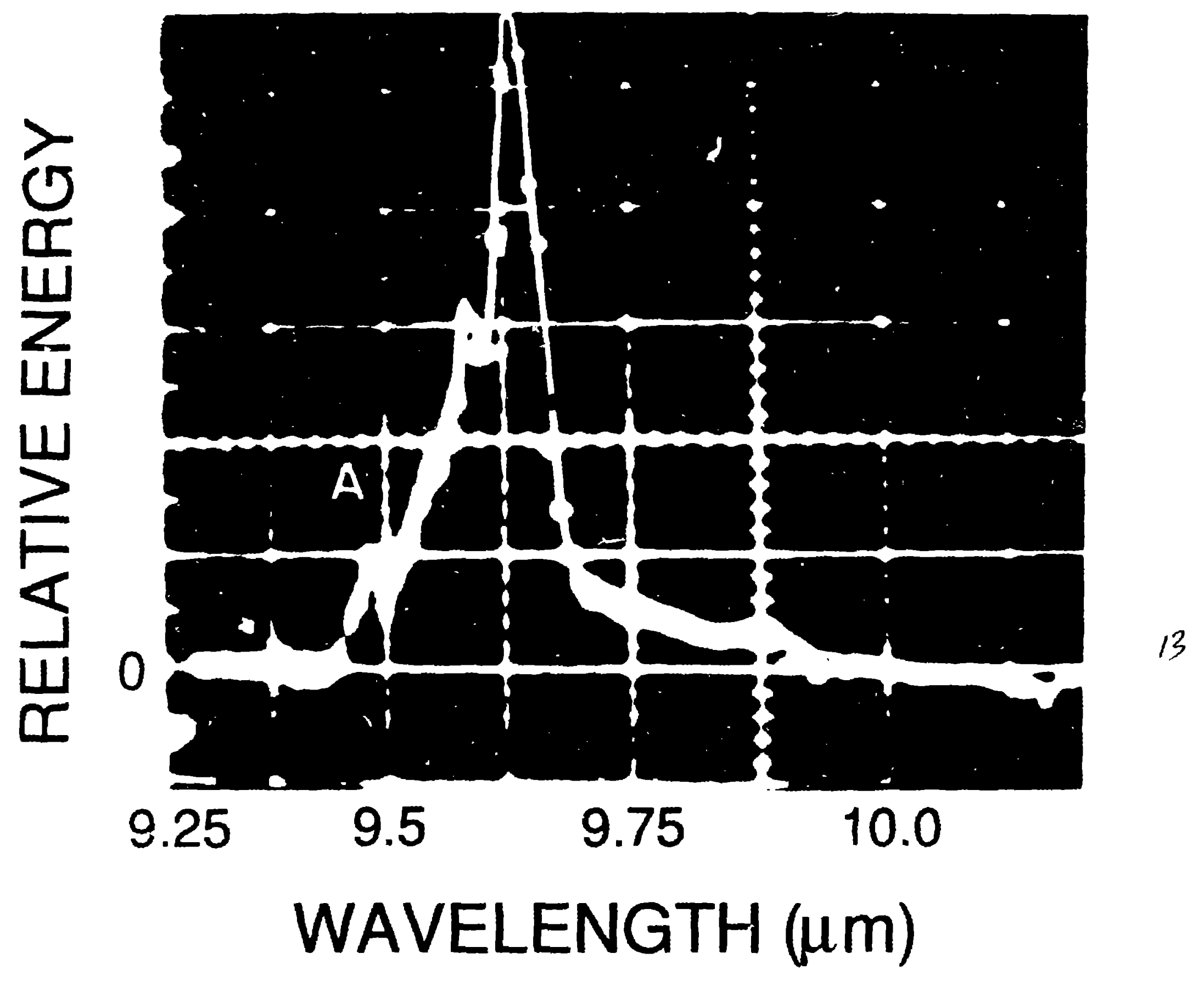




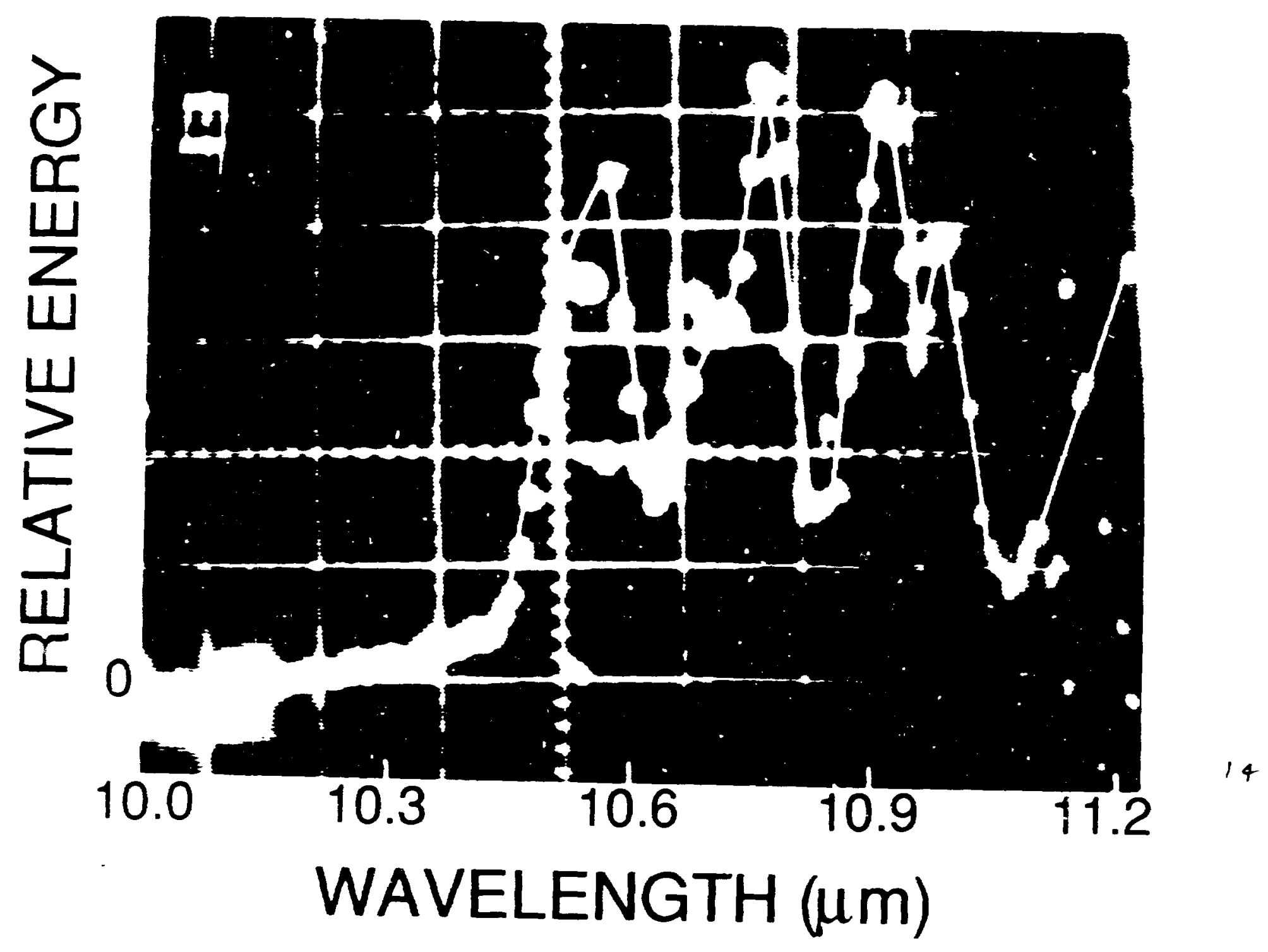



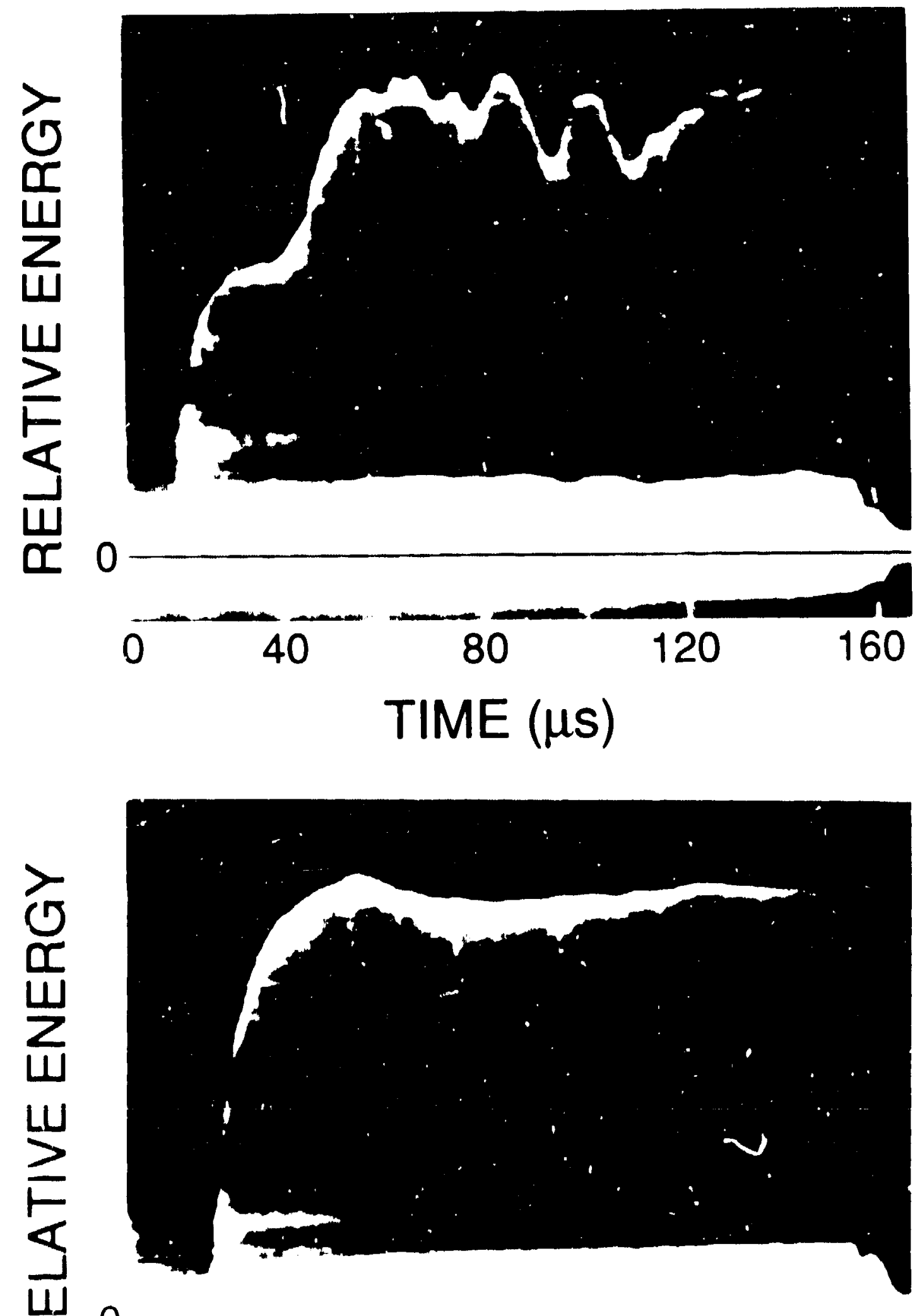

늠 